\title{
EAl Endorsed Transactions

\section{Digital Society and Economy for People with Disabilities in Industry 4.0 : Malaysia Perspectives}

\author{
Ruhiyati Idayu Abu Talib ${ }^{1,2, *}$, Mohd Shahrizal Sunar ${ }^{1, *}$, Ruzimi Mohamed $^{2}$ \\ ${ }^{1}$ Media and Game Innovation Centre of Excellence (MaGIX), Institute of Human Centered Engineering(iHumEn), \\ Universiti Teknologi Malaysia(UTM), Malaysia \\ ${ }^{2}$ School of Computing,Faculty of Engineering, Universiti Teknologi Malaysia (UTM), Malaysia
}

Abstract

One of the key trends driving revolution in Industry 4.0 is digital society and economy. In this paper, we argue that the advancement of technology in Industry 4.0, which covers growth areas such as big data and machine learning, cybersecurity, digital currencies, blockchain and the Internet of Things (IoT) with expected creations of new job opportunities in the areas of Cyber Security, Data Analytics, Network Infrastructure and Software Development that can easily be done at home, has produced an ideal scenario in the context of job opportunities for People with Disabilities (PWDs). Greater accessibility to education with help from assistive technology opens up a lot of opportunities for PWDs to enhance their knowledge in Industry 4.0.

Received on 02 July 2019; accepted on 13 July 2019; published on 16 July 2019

Keywords: Industry 4.0, Person with Disabilities, Internet of Things (IoT), Digital Economy, Digital Society, Virtual Reality, Augmented Reality, Technopreneur, Empowerment, Enabler.

Copyright (C) 2019 Ruhiyati Idayu Abu Talib et al., licensed to EAI. This is an open access article distributed under the terms of the Creative Commons Attribution license (http://creativecommons.org/licenses/by/3.0/), which permits unlimited use, distribution and reproduction in any medium so long as the original work is properly cited.

doi:10.4108/eai.30-7-2019.162949

\section{Introduction}

Disability, the preferred term for impairments, limitations of movement and constraints of participation refers to the unique phenomenon that reflects an interaction between the characteristics of the body of a person and the attributes of the society in which he or she is. Disability is not defined by the need to use a wheelchair, but rather by the stairs that doesn't have accompanying ramp or elevator. It is an complex relationship between physically or mentally impaired persons and their environment, social and situational circumstances.

Based on the World Health Organization's (WHO) estimates, in developing countries, the number of people with disabilities range between $5 \%$ and $10 \%$ [6]. The World Bank estimated that the total national income losses ranged from US\$ 1,370 billion to US\$

\footnotetext{
$\star$ The first version of the paper was accepted at the INTETAIN 2019 Conference

*Corresponding author. Email: ruhiyati.magicx@gmail.com, shahrizal@utm.my
}

1,940 billion worldwide, due to the exclusion of people with disabilities from mainstream society[12].

A study conducted by the Institute for Public Health, Ministry of Health Malaysia in 2015, to supplement existing data and provide data for monitoring and evaluation of health programs implemented by the Ministry of Health, found that the prevalence of disability among adults in Malaysia was $11.8 \%$, based on a sample survey of 19,959 healthy adults with ages between 18 to 50 years [2]. This survey supported WHO's estimate of the number of disabilities in Malaysia. There is an urgent need to create a future in which they participate more actively in society, a future which increases their independence and in which they are able to make decisions about their lives and futures, by offering them opportunities for employment and access to essential services.

Many of the initiatives either by public sectors or private sectors, for PWDs do not address the root of the problem which is re-setting the mindset of the society from the charity based model[11] to the social right based model[18]. The charity model views disabled people as victims of their impairment(s) and disability is considered a weakness. This model 
reinforces negative disability stereotypical views as it does not address individuals' unique qualities or their ability to be active and participating members of society. On the other hand, the social model reflects on the constraints that exist in society- largely due to how structures, buildings and procedures are built without taking into account the needs of othersand how those barriers can be minimized to ensure full and equal inclusion for people with disabilities in society. That, along with the rights-based modelwhich recognizes disability as an integral aspect of human culture, and affirms that all human beings have certain constitutional protections that are universal rights regardless of their disabilities. This focuses on empowering the PWDs. By enabling these presumably disabled people to function to their full potential, they can study, work, be independent, lead dignified and meaningful lives- just like their non-disabled peers.

The current technological and digital environment are enabler that facilitate social inclusion, because it allows for the delivery of real-time services that can enable individuals to learn, work, travel, socialize, shop, and interact with the community without being subject to physical barriers.

Growth in technology-enabled digital platforms - changing the very nature of how people are doing business away from the traditional brick and mortar model, will continue to intensify the rise of independent work. These changes are not only impacting the normal person but also transforming the prevalence and functional impact of PWDs, the scale of social disparities in disability, and perhaps the essential meaning of disability in an increasingly technologydominated world. The question now is, how can these successes extend to PWDs?

\section{Employment, Self-Employment and Entrepreneurship for People with Disabilities}

Landscape of the PWDs in Malaysia shown that there are 453,258 people registered as PWDs to the Department of Social Welfare (DSW) which consist of $1.39 \%$ of Malaysia total population (32.3 million in 2018). These data are incomplete, however, as registration of people with disabilities in Malaysia is not mandatory and is done on a voluntary basis only. Among the reasons why PWDs are reluctant register with DSW is due to negative stigma attached to the tittle. Disability affects a wide range of socio-economic outcomes, including labour market participation, but also other factors that shape participation, including education, information and transport. Disabled people experience lower labour market participation rates than the non-disabled throughout the world.
There are a number of literature studies discussing the challenges for PWDs regarding their job opportunities in the labor force $[25,26,13]$. Among the challenges are [10]:

(i) Inaccessible transportation

(ii) Inaccessible buildings

(iii) Negative attitudes by employers

(iv) Low self-esteem

\section{(v) Overprotective families}

Lack of appropriate transportation facilities is a major barrier to PWD employment. Secondly is the stigma and prejudice of employers and society to PWDs. Taking example from Malaysia, the Labor Force's 2017 report (Fig. 1) showed that there are a total of 303,000 PWDs outside the labor force, which translate into total national income losses ranging from US\$ 1.18 billion to US\$ 1.68 billion according to the World Bank estimate [12].

From 1999 to 2001, a total of 4,017 disabled workers were registered with the Labor Department. Out of these 4,017, a total of 2,529 people with disabilities were placed in various job sectors. Khor (2010) noted that despite the $1 \%$ quota, the public sector employed only 581 people and the private sector employed less than 5,000 people with disabilities [12]. One possible solution to problems of low participation rates lies in the potential for disabled people to become selfemployed or to start and run their own businesses. Since the terms self-employed and entrepreneur are closely linked [24], we refer to the following definitions and will continue to use both terms synonymously:

Self-employment : Those who work for profit or fees in their own business, profession, trade or operate a farm [3].

Entrepreneurship : A combination of the activities discovery, evaluation and exploitation of opportunities to introduce e. g. goods and services, processes and organization structures that were not existent before[19],

A Technopreneur: on the other hand, is one of the major extensions of entrepreneurship, based on the U.S. legal definition [27].

A Technopreneur is a new age entrepreneur who uses technology to make innovations and comes out with something new. Technopreneurs operate differently from those in the current economic order, by optimizing the use of technology to innovate new products and services that create a marketplace disruption. For example, Uber's founders thought (Idea) of a different way of calling a cab (market gap), used the power of technology (built an integrated GPS app) and changed the taxi / cab industry's economy completely. To compete in today's global landscape, it is essential to use state-of the-art technologies such as computer systems, 
Figure 1. Population Outside Labour Force by Reasons for not Seeking Work, Malaysia, 2016 and 2017 (Source from: Statistic Department of Malaysia)[21]

\begin{tabular}{|l|r|r|r|r|}
\hline \multirow{2}{*}{ Reasons for not seeking work } & \multicolumn{2}{|c|}{ ('000) } & \multicolumn{2}{c|}{ (\%) } \\
\cline { 2 - 5 } & \multicolumn{1}{|c|}{2016} & 2017 & 2016 & 2017 \\
\hline Total & $6,987.6$ & $7,042.9$ & 100.0 & 100.0 \\
\hline Schooling & $3,002.8$ & $3,008.8$ & 43.0 & 42.7 \\
\hline Housework/family responsibilities & $2,906.5$ & $2,905.0$ & 41.6 & 41.2 \\
\hline Going for further studies & 155.3 & 153.3 & 2.2 & 2.2 \\
\hline Disabled & 274.1 & 303.2 & 3.9 & 4.3 \\
\hline Not interested & 88.2 & 75.8 & 1.3 & 1.1 \\
\hline Retired & 560.7 & 597.7 & 8.0 & 8.5 \\
\hline
\end{tabular}

including software and hardware, or manufacturing processes. However, the efficient and successful use of ordinary technology subject to the context, requires specific capabilities. Typical requirements include, the ability to perceive technology, the ability to work with technology, and the ability to understand technology.

\subsection{Technoprenuership and PWDs}

Being an entrepreneur affords individuals with a certain degree of independence [23], which is crucial for PWDs as they are very unique individuals that require a certain type of environment to thrive in. At the same time, entrepreneurship demands from its entrepreneurs a tenacity and strong self-motivation to succeed [20].

According to the Flow Theory of Csikszentmihalyi, motivation can be achieved or maintained if the capabilities of a person are sufficient to meet the requirements of a particular situation. If the capacity of a person is insufficient for the task, it is more likely to be abandoned by the individual [5]. PWDs are often at a disadvantage when it comes to handling a complex situation such as entrepreneurship. The task for PWDs is much more difficult and at times even impossible, compared to people without disabilities. They lack specific capabilities due to their disability, e.g., visual or mobile capabilities, which worsen their chance to compete in the market.Research showed that PWDs are still lagging behind in education systems, thereby placing them at a disadvantage in terms of job opportunities in the open market. Educational inferiority can easily reduce self-motivation, which could also result in damaged self-esteem [22].

Technology is an important factor in achieving and maintaining self-motivation and self-esteem for PWDs, and it also helps them in participating in the social environment [9]. Assistive technologies (AT), accessible websites and accessible applications make it possible for PWDs to become part of the society $[17,1]$. For instance, artificial limbs, retina implants or screen readers that enhance inclusion and self-esteem. Additionally, technology is also a critical factor in today's business startups.

People with higher education level would generally imply a greater ability to use technology [16]. However, people with disabilities such as physical or cognitive impairments, are often limited with respect to these capabilities, even if they are highly educated. In most cases, this is due to inadequate technologies that do not meet PWDs requirements. Therefore, PWDs are often unable to make efficient use of technology. This means that PWDs have disadvantages in obtaining independent individuality (perspective of individuals) as well as information necessary for entrepreneurship (perspective of information society), in addition to overcoming barriers in order to organize their businesses in a competitive manner (perspective of business organization). 
The OECD report provides a better understanding of the complexity of this multifaceted topic, with specific recommendations for policy actions in order to promote the self-employment of people with disabilities [28]. The first suggestion that can be derived from this article concerns the need for IT accessibility laws to be regulated and tightened, particularly for public institutions. Secondly, the policy requires an accessible educational framework to ensure that more students with disabilities are able to complete their college degrees and thus build a proper basis for selfemployment. Thirdly, it is strongly recommended that the AT market be consolidated and standardized to ensure the high-quality supply and dissemination of suitable AT and innovative services for people with disabilities to help them start their own businesses. Ultimately, by advertising and funding such RD projects, policies can attract attention and efforts, which can help in developing and evaluating accessible technologies for disabled entrepreneurs [28].

In Fig.2, we illustrate our points in these sections about disabled entrepreneurship for clearer understanding.

In Malaysia, there are 10 core strategic planning with one mission under the DSW "Pelan Tindakan OKU 2016-2022" to create a society without barriers for PWDs, including the creation of an entrepreneurial ecosystem to meet the needs of PWDs.

\subsection{The Digital Literacy for PWDs}

A generation ago, IT and digital media were niche skills. Today, they are a core competency necessary to succeed in most careers. Without a digital literacy programme, command of and access to technology will be distributed unevenly, exacerbating inequality and hindering socio-economic mobility. The challenge is to move beyond thinking of IT as a tool instead we need to start thinking on how to nurture's people's ability and confidence to excel both online and offline in a world where digital media is ubiquitous. World Economic Forum (WEF) coins a new phase called "Digital Intelligence or DQ"[15] According to WEF, DQ can broadly be broken down into three parts (Table 1):

This digital transformation trends is one of four driving force behind Industrial 4.0 revolutions. By 2022 , an estimated $60 \%$ of global GDP will be digitized, and in the context of PWDs, technology plays an important part in making their lives better. Therefore, for PWDs community, digital literacy program related to Industry 4.0 is necessary to prepare them for Industry 4.0.

There are five core skills that's related to Industry 4.0; Web Technology

(i) Internet of Things (IoT)
Table 1. Level of Digital Intelligence

\begin{tabular}{|l|l|}
\hline Digital & $\begin{array}{l}\text { The ability to use digi- } \\
\text { tal technology and media } \\
\text { in safe, responsible and } \\
\text { effective ways }\end{array}$ \\
\hline Digital & $\begin{array}{l}\text { The ability to use digi- } \\
\text { tal technology and media } \\
\text { in safe, responsible and } \\
\text { effective ways }\end{array}$ \\
\hline $\begin{array}{l}\text { Digital } \\
\text { shipepreneur }\end{array}$ & $\begin{array}{l}\text { The ability to use digi- } \\
\text { tal media and technolo- } \\
\text { gies to solve global chal- } \\
\text { lenges or to create new } \\
\text { opportunities }\end{array}$ \\
\hline
\end{tabular}

(ii) AR/VR Technology

(iii) Cloud Computing

(iv) Cyber Security

The idea is to develop a productive PWDs that is able to ;

(i) Apply knowledge, understanding and practical skills in industrial 4.0 work process

(ii) Make judgments and decisions that take into account social, scientific and ethical issues with moderate autonomy.

(iii) Demonstrates the confidence and entrepreneurship to generate their own work.

(iv) Demonstrates accountability as a member of the national and international community.

(v) Demonstrates learning skills to adapt to new ideas, processes and procedures for professional / career development.

(vi) Demonstrates teamwork, communication skills and communicates information, ideas, problems and solutions effectively.

The aim is to build a talent capable of producing creative and innovative technologies in Industry 4.0 and being able to come out as a technoprenuer with the best solutions.

In Asia, there are certain roles being assign to gender by society i.e man's role as head of the house and woman's role as a caretaker of the house. This gender role value in turn affected how people are making decision when pursuing their education and career. Unfortunately, the field of STEM are still seen as strongly dominated by male. This is crucial because for women from PWDs, the first thing that individuals 


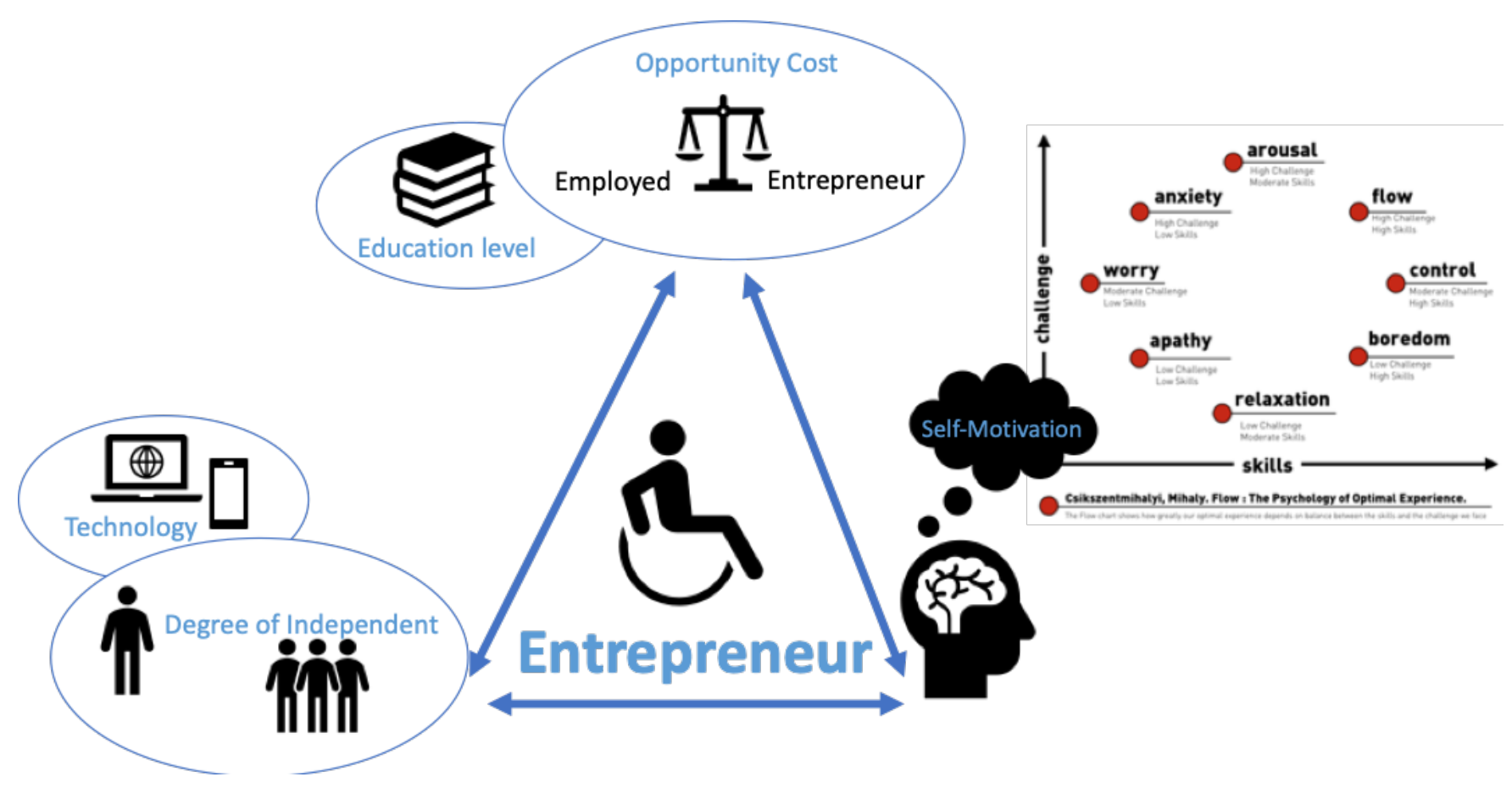

Figure 2. Technology, Self-Motivation and Entrepreneurship

notice is their physical disability rather than their capacity, combining that with the existing gender role value that are generally in place for women makes it triple-hard for them to succeed in science and technology.

Visible barriers such as accessible learning material and universal design facilities in school and colleges are a much more obvious challenges that the government needs to address but invisible barriers such as gender value role are much harder to identified. At the same time, PWDs as underrepresented groups in STEM areas, their real preferences due to cognitive dissonance[7] must also be understood. Do they shy away from STEM due to lack of facilities available for them or because of some other preference that government are yet to identified?

The reason we mention cognitive dissonance theory is because in part, it acts as a motivating force in people's lives. Individuals are motivated to reduce discrepancies that produce aversive affective states (e.g., the discomfort arising from the awareness that although one wants to lead a healthy lifestyle over the past 2 weeks, she or he has not exercised). This could be explored in another separate research to identified cognitive dissonance arousal regarding PWDs participants in STEM and finding ways to reduce it will lead to better policy to increase participation of PWDs in science and technology.

\section{PWDs Technopreneur Ecosystem}

There has been a paradigm shift over the years when it comes to dealing with PWD issues. Before, the approach taken a in dealing with PWD issues was more about a Charity Model Disability[11], that had no specific plan and policy aimed at improving their quality of life and well-being.

United Nations Convention on the Rights of Persons with Disabilities (UNCRPD)was put in effect on 3 May 2008 and in November 2012, members of the United Nations Economic and Social Commission for Asia and the Pacific (UNESCAP) adopted the "Making the Right Real" strategy for PWDs in Asia and the Pacific, which included 10 goals and 62 indicators. This was to serve as part of strategy for moving forward towards building a stronger policy framework for mainstream disabled people and ensuring their effective participation in the society. UNCRPD defined disability in accordance with the Social Model Disability [18], that recognized disability as an evolving concept and also noted that disability was the result of interactions between people with disabilities, and attitudinal and environmental barriers that impede their full and effective participation in society on an equal footing with people without disabilities.

A collective effort of multi-sectoral and multi-agency collaboration with other relevant agencies will be needed in order to develop an ecosystem specific to the development of Technoprenuer for PWDs. This is 
to ensure sustainability and to achieve comprehensive and holistic results. As PWDs, their needs are different from able person. Another aspect of the ecosystem is collaboration with corporate company such as Microsoft (AR / VR) and Legoland (3D Modeling) for up-to-date and industry-relevant knowledge. aWe summarised the concept as illustrate in Fig.3.

Assistive technology is an umbrella term covering the systems and services related to the delivery of assistive products and services. Assistive products maintain or improve an individual's functioning and independence, thereby promoting their well-being. Structure development in this industry is important for acceleration of technoprenuer program for PWDs.It should be developed further for them, and should be guided by the underlying principle that in all actions involving persons with disabilities, their interests and needs should be taken into account; whether undertaken by individuals, public or private social welfare institutions, courts of law, administrative authorities or legislative bodies or entities; recognizing that inclusion and mainstreaming should be promoted and specialized.

\subsection{Malaysia Perspectives: Public and Private Sectors Initiatives}

Malaysia has various policies, laws and standards for the benefit of PWDs yet there is no stringent implementation of the policies. Despite PWD act enacted in 2008, PWDs are still considered as one of the most vulnerable of the minority group in the Malaysian population1. There are numerous forms of open debate on equal rights and the quality of life of individuals with disabilities in Malaysia. Unfortunately, their opinions are often excluded from decisions that affect their welfare and livelihoods. Most importantly, a large number of PWDs are socially excluded in Malaysia and out of the mainstream development2. Meanwhile, the convenience of technology to some degree transcends the physical and mental impairment of PWDs. With the technology devices specifically tailored to meet the individual's needs, PWDs can improve and optimise their daily functioning, allowing them to become independent, self-sufficient and selfconfident.

The responsibilities of implementing a national plan and policy regarding PWD fall under the jurisdiction of the National Council for Persons with Disabilities (NCPWD), chaired by the Ministry of Women, Family and Community Development (MWFCD). NCPWD recognized that a collective effort through multi-sectoral and multi-agency collaboration with other relevant agencies was needed to achieve comprehensive and holistic results. There are a number of government agencies that cater to the matter of entrepreneurship. For example, Majlis Amanah Rakyat (MARA) or The Trust Council for Bumiputera, a statutory agency, has been given the government's mandate to develop successful and innovative Bumiputera entrepreneurs who are empowered with global human capital and integrity, and who contribute to increased equity ownership in return. MARA has a dual role to play in the development of education and entrepreneurship. MARA has successfully implemented its educational transformation in Technical and Vocational Education and Training (TVET) in line with its slogan, "Entrepreneurship and Global Education", combining with the ethos of entrepreneurship to develop "glocal" technoprenuers. Although MARA has successfully developed and implemented technoprenuer syllabus for theintrepreneurs, this is only for the those non-disabled. We can hardly get data from them about the number of disabled entrepreneurs due to the low numbers they have and to their inconsistency in keeping records of PWD entrepreneurs.

There are very few government agencies that provide specific initiatives for PWD entrepreneurs. One of that is the Malaysia Welfare Department which has introduced a grant scheme to enable eligible PWDs to expand their businesses; known as "Skim Galakan Perniagaan Orang Kurang Upaya (SB-OKU)". A total of RM 16 million has been budgeted for this scheme, which has benefited a total of 1,563 PWDs as of 2014 . Analysis of the current government infrastructure for PWDs showed that it is an extension of existing infrastructure available to ordinary people or people with no disabilities.

The existing approach to PWD issues is close the gap between normal people and PWDs through a lens of a non-disabled people's perspectives. But if we agree that disability is a direct result of a hostile environment (Social Disability Model) rather than physical and mental disability (Medical Disability Model)[4], then we must change our approach by trying to close the gap between PWDs and normal people, through PWDs perspective. For example, looking at the situation from a blind person's perspective might help us ask questions like - What if we live in a world without light? How will we do business? How can we create a nonvisually dependent business environment? What kind of skills are needed to survive in that alternate world? Eight years after the government introduced inclusive development as the national agenda, the results were found, and the data was not encouraging.

Although there is an increasing awareness of the demand to have more PWD entrepreneurs in the market, the private sector has been very slow on the uptake. Currently, only the Maybank Foundation has developed a holistic entrepreneur ecosystem that specifically targets minorities in Malaysia [8].Reach Independent and Sustainable Entrepreneur (R.I.S.E) 


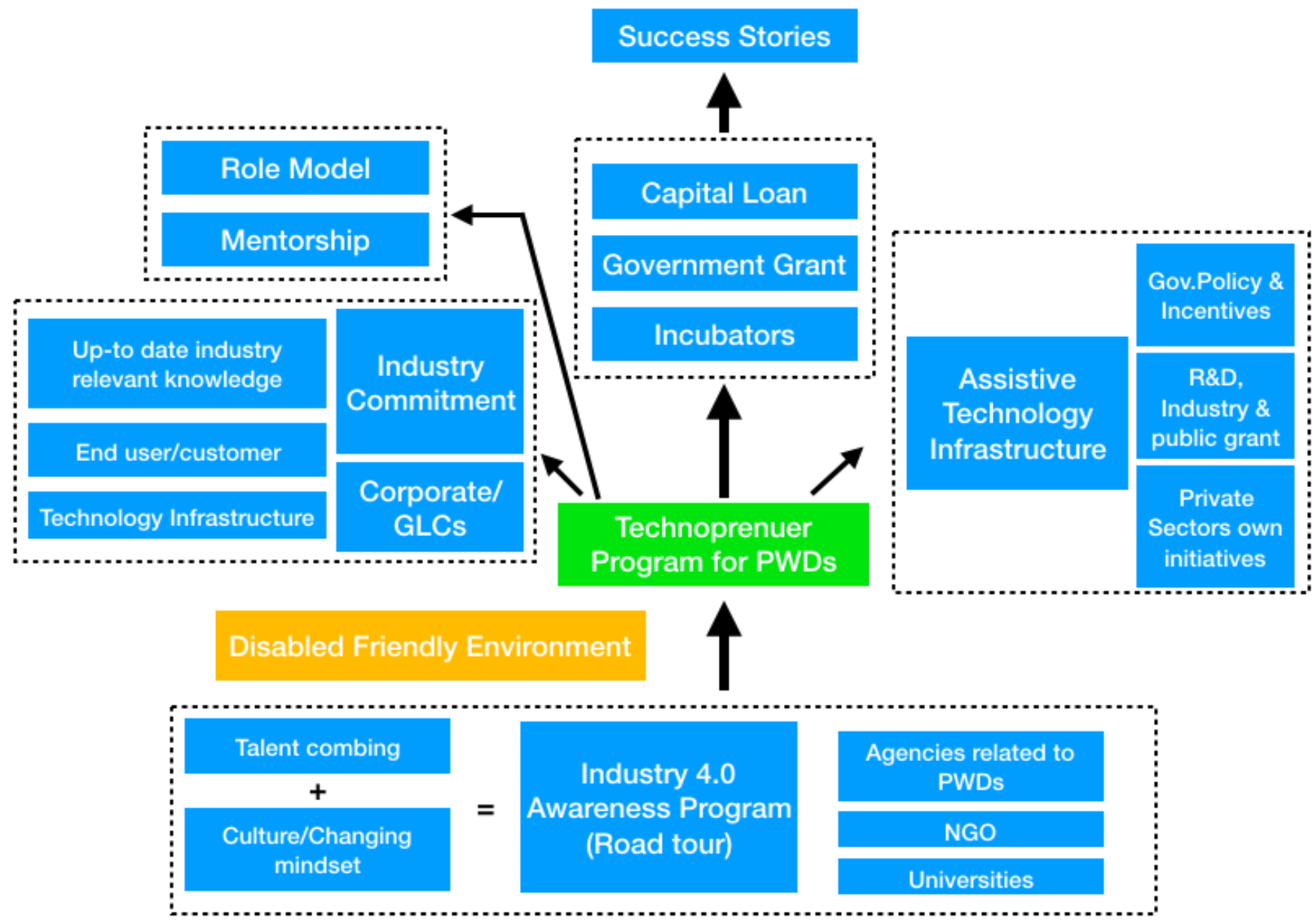

Figure 3. Proposed PWDs Technoprenuer Ecosystem Framework

program is designed to train, coach and mentor participants to develop their entrepreneurial skills, resulting in higher income levels, and thus improving their overall standard of living. The key features of the program include; Practical entrepreneurship training, Effective mentoring and focus on income improvement, and Large-scale involvement of Maybank employees. Currently R.I.S.E is in phase 2 and has successfully trained 1,080 PWDs with the top $40 \%$ result for the initial 280 participants involved in the pilot project in Malaysia. This pilot project was started in September 2014, and has an average income increase as highlighted below:

(i) Per participants in RISE is $411.7 \%$;

(ii) Income Increase from RM 462.50 to RM 2,366.47;

(iii) Average Income Increase RM 1,903.97

The R.I.S.E. programme starts with a three-day training on entrepreneurship and financial management. This is followed by three to six months of mentoring with a special focus on motivating participants. After the programme, participants continue to be guided and introduced to business opportunities. Their incomegeneration ability is also monitored. Maybank does not provide special loans to the R.I.S.E. participants but supports them to become eligible for standard loans. The training has enabled participants to build innovative sales strategies into their business ideas, enhance business management skills and augment client acquisition and retention, resulting in greater financial independence and increased resilience in businesses. The fourth industrial revolution is changing the global economic landscape, covering growth areas such as big data and machine learning, cybersecurity, digital currencies, blockchain and the Internet of Things (IoT), with an expected creation of 30,000 jobs by 2020 in ASEAN alone. New areas like Cyber Security, Data Analytics, Network Infrastructure and Software Development will replace major job areas in the world and make the traditional workforce obsolete [9]. Emerging job positions such as digital content creators, programmers, social media managers, which can easily be done at 
home, are ideal positions in the context of job opportunities for PWDs.

\section{Conclusion}

Disabled people experience higher unemployment rates, economic inactivity and lack of social protection compared to their non-disabled peers. Research shows that there are economic and business benefits for PWDs inclusion. These include the benefits for economies as a whole, for companies that adopt various practices, and for people with disabilities themselves. In the era of the fourth industrial, the constraints of physical impairment should no longer applies due to the divergent of technology available. Technologies enable a more flexible working environment, better involvement in PWD's workforce and a range of new jobs [14].Referring to a report from OECD, PWDs in parts of Europe, are encourage to become self-employed or entrepreneurs[28].In many cases, people with disabilities do not have the necessary entrepreneurial skills because their education is inferior. This disability can reduce self-motivation easily, ending in damaged self-esteem. Under these circumstances, entrepreneur's experience is much more unlikely. Therefore, in order to boost the entrepreneurship of disabled individuals, it is essential to ensure self-motivation and self-esteem by removing disadvantages for PWDs.

In Asia especially South East Asia, "technoprenuer" or entrepreneurs that uses cutting-edge technology to develop new business are the main driver for business creations for the past 10 years. It is useful to understand different natures of technoprenuer. Different natures of technoprenuer required different types of skills sets and uses different types of technology. One is technology developer, those who develop a unique technology capable of driving new businesses such as Apple, Tesla and Microsoft. Second is technology user, those who see a new technology development and understand how it can be applied to meet a market need. Example of technology users are Uber, Airbnb and Amazon. As mention earlier in the report, the efficient and successful use of ordinary technology subject to the context, requires specific capabilities. Typical requirements include;

(i) The ability to perceive technology;

(ii) The ability to work with technology; and

(iii) The ability to understand technology.

The proposed framework (Figure 3 ) has been built with these 3 assumptions in mind and is sufficient to initiate PWD-specific technopreneur program. There is potential for PWDs to become technoprenuer, and more PWDs to become technoprenuer should be supported by public and private sectors.

\section{Acknowledgement}

Deepestgratitude to Malaysia Technology Development Corporation (MTDC) and Universiti Teknologi Malaysia (UTM) for supporting our ongoing research that will allow us to identify suitable technopreneur skills that PWDs need and the level of their knowledge that will give them the opportunity to participate actively in Industry 4.0 movement and taking advantages of an advancement in technology to change how they are interacting with the society.

\section{References}

[1] Fouzia Khursheed Ahmad. "Use of assistive technology in inclusive education: Making room for diverse learning needs". In: Transcience 6.2 (2015), pp. 62-77.

[2] Noor Ani Ahmad et al. "Prevalence and determinants of disability among adults in Malaysia: results from the National Health and Morbidity Survey (NHMS) 2015". In: BMC public health 17.1 (2017), p. 756.

[3] Eugene H Becker. "Self-employed workers: an update to 1983”. In: Monthly Lab. Rev. 107 (1984), p. 14.

[4] Simon Brisenden. "Independent living and the medical model of disability". In: Disability, Handicap \& Society 1.2 (1986), pp. 173-178.

[5] Mihaly Csikszentmihalyi and Isabella Selega Csikszentmihalyi. Optimal experience: Psychological studies of flow in consciousness. Cambridge university press, 1992.

[6] Disability and health. https : / / www . who. int / news room/fact-sheets/detail/disability-and-health. (Accessed on 05/09/2019).

[7] Leon Festinger. A theory of cognitive dissonance. Vol. 2. Stanford university press, 1962.

[8] Maybank Foundation. Sustainability Reports. https : // maybankfoundation. com/index . php/media-center / sustainability-reports. (Accessed on 05/13/2019). 2017.

[9] David Halabisky. "Entrepreneurial Activities in Europe-Entrepreneurship for People with Disabilities". In: (2014).

[10] Robert Heron and Barbara Murray. "Assisting disabled persons in finding employment: A practical guide". In: (2003).

[11] Arlene S Kanter. The development of disability rights under international law: From charity to human rights. Routledge, 2014.

[12] HT Khor. "Turning disability into a national asset". In: Penang Economic Monthly (2010), pp. 16-20.

[13] Melissa Ng Lee, Yen Abdullah, and See Ching Mey. "Employment of People with Disabilities in Malaysia: Drivers and Inhibitors." In: International Journal of Special Education 26.1 (2011), pp. 112-124.

[14] Nigel Meager and Tom Higgins. "Disability and skills in a changing economy". In: UK Commission for Employment and Skills, Briefing Paper Series, http://www. oph. fi/download/140962_equality-disability. pdf (2011). 
[15] Yuhyun Park. 8 digital life skills all children need - and a plan for teaching them | World Economic Forum. https: / / www . weforum . org/agenda / 2016/09/8-digitallife-skills-all-children-need-and-a - planfor-teaching-them. (Accessed on 12/10/2019). Sept. 2016.

[16] James B Pick and Rasool Azari. "Worldwide digital divide: influences of education, workforce, economic, and policy factors on information technology". In: Proceedings of the 2007 ACM SIGMIS CPR conference on Computer personnel research: The global information technology workforce. ACM. 2007, pp. 78-86.

[17] Kathryn E Ringland et al. "Would you be mine: Appropriating minecraft as an assistive technology for youth with autism". In: Proceedings of the 18th International ACM SIGACCESS Conference on Computers and Accessibility. ACM. 2016, pp. 33-41.

[18] Torn Shakespeare and Nicholas Watson. "The social model of disability: an outdated ideology?" In: Exploring theories and expanding methodologies: Where we are and where we need to go. Emerald Group Publishing Limited, 2001, pp. 9-28.

[19] Scott Andrew Shane. A general theory of entrepreneurship: The individual-opportunity nexus. Edward Elgar Publishing, 2003.

[20] Scott Shane, Edwin A Locke, and Christopher J Collins. "Entrepreneurial motivation". In: Human resource management review 13.2 (2003), pp. 257-279.

[21] Department of Statistic Malaysia. Labour Force Survey Report, Malaysia, 2017. https : / / www . dosm . gov . my / v1 / index . php ? $r=$ column / pdfPrev \& id = aEdIelhlVTBtOHh j0UxqcXhyc2pCUT09. (Accessed on $05 / 16 / 2019)$. 2017.

[22] CLAUDE M STEELE. "Stereotypes and the fragility of academic competence, motivation, and self-concept". In: Handbook of competence and motivation (2013), p. 436.

[23] Ute Stephan et al. "Understanding motivations for entrepreneurship". In: BIS Research paper 212 (2015).

[24] Jolanta Szaban et al. "Self-employment and entrepreneurship: A theoretical approach". In: Journal of Management and Business Administration. Central Europe 26.2 (2018), pp. 89-120.

[25] Tiun Ling Ta and Khoo Suet Leng. "Challenges faced by malaysians with disabilities in the world of employment". In: Disability, CBR \& Inclusive Development 24.1 (2013), pp. 6-21.

[26] Tiun Ling Ta, Lee Lay Wah, and Khoo Suet Leng. "Employability of people with disabilities in the northern states of peninsular Malaysia: Employers' perspective". In: Disability, CBR \& Inclusive Development 22.2 (2011), pp. 79-94.

[27] Inc USLegal. Technopreneur Law and Legal Definition. https : / / definitions. uslegal. com / t / technopreneur/. (Accessed on 05/09/2019).

[28] D Vaziri et al. "Disabled entrepreneurship and selfemployment: The role of technology and policy building". In: (2014). 